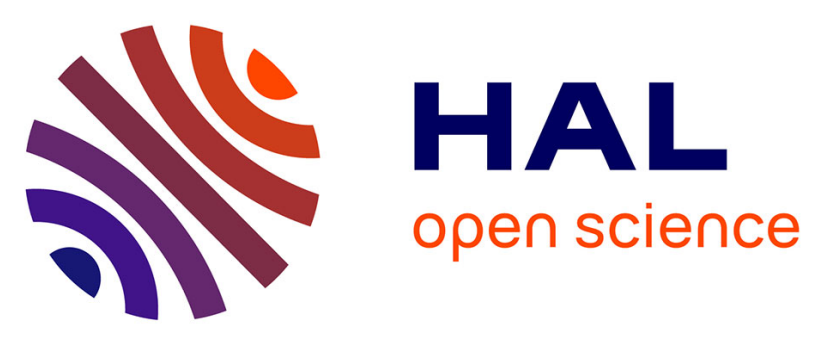

\title{
Aligned carbon nanotube based ultrasonic microtransducers for durability monitoring in civil engineering
}

Bérengère Lebental, Pierre Chainais, Pascale Chenevier, Nicolas Chevalier, Eric Delevoye, Jean-Marc Fabbri, Sergio Nicoletti, Philippe Renaux, Anne Ghis

\section{To cite this version:}

Bérengère Lebental, Pierre Chainais, Pascale Chenevier, Nicolas Chevalier, Eric Delevoye, et al.. Aligned carbon nanotube based ultrasonic microtransducers for durability monitoring in civil engineering. Nanotechnology, 2011, 22 (39), pp.395501. 10.1088/0957-4484/22/39/395501 . hal-00707637

\section{HAL Id: hal-00707637 https://hal.science/hal-00707637}

Submitted on 13 Jun 2012

HAL is a multi-disciplinary open access archive for the deposit and dissemination of scientific research documents, whether they are published or not. The documents may come from teaching and research institutions in France or abroad, or from public or private research centers.
L'archive ouverte pluridisciplinaire HAL, est destinée au dépôt et à la diffusion de documents scientifiques de niveau recherche, publiés ou non, émanant des établissements d'enseignement et de recherche français ou étrangers, des laboratoires publics ou privés. 


\title{
Aligned carbon nanotubes based ultrasonic microtransducers for durability monitoring in civil engineering
}

\author{
B Lebental ${ }^{1,5}$, P Chainais ${ }^{2,6}$, P Chenevier ${ }^{3}$, N Chevalier ${ }^{4}$, E Delevoye ${ }^{4}$, J-M \\ Fabbri $^{4}$, S Nicoletti $^{4}$, Penaux $^{4}$ and A Ghis ${ }^{4}$ \\ ${ }^{1}$ Université Paris-Est, IFSTTAR, 58 boulevard Lefebvre 75732 Paris Cedex 15, France \\ ${ }^{2}$ INRIA Lille-Nord Europe (SEQUEL), 40 avenue Halley 59650 Villeneuve d'Ascq France \\ ${ }^{3}$ LEM, SPEC (CNRS URA 2464), CEA, IRAMIS, Gif sur Yvette, France \\ ${ }^{4}$ CEA-LETI, Minatec Campus, 17 rue des Martyrs 38054 Grenoble Cedex 9, France \\ E-mail: berengere.lebental@ifsttar.fr
}

\begin{abstract}
Structural health monitoring of porous materials such as concrete is becoming a major stake in our resource-limited economy, as it conditions durable exploitation of existing facilities. Durability in porous materials depends on nanoscale features which need to be monitored in-situ with nanometric resolution. To address this problem, we put forward an approach based on the development of a new nanosensor, namely a capacitive micrometric ultrasonic transducer whose vibrating membrane is made of aligned single-walled carbon nanotubes (SWNT). Such sensors are meant to be embedded in large number within a porous material in order to provide with information on its durability by monitoring in-situ neighboring individual micropores. In the present paper, we report on the feasibility of the key building block of the proposed sensor: we have fabricated well-aligned, ultra-thin, dense SWNT membranes that show above-nanometer amplitudes of vibration in a large range of frequencies spanning from $100 \mathrm{kHz}$ to $5 \mathrm{MHz}$.
\end{abstract}

PACS: 07.07.Df, 68.37.-d, 85.35.Kt, 85.85.+j

\section{Introduction}

Because cement manufacturing represents $7 \%$ of the world-wide industrial energy consumption and $4 \%$ of the worldwide industrial $\mathrm{CO}_{2}$ emission, reducing its ecological footprint has become an environmental priority [1]. By improving structural efficiency and durability, nanotechnologies open the path toward a greener construction industry [2]. Two domains appear most promising: nanocomposites construction materials [3], which have shown both high performance [4] and new functionalities [1], and nanosensors, which are used for structural health monitoring, notably for the measurement of macroscopic structural properties like damage, strain or corrosion [5].

The in-situ monitoring of micro and nano-scale features by a large number of embedded nanosensors is not yet addressed, although the random micro- and nanoporosities of cement-based structures play a most significant role in their durability issues [6]. To fill this gap, a relevant path consists in probing individual capillary pores $(10 \mathrm{~nm}$ to $10 \mu \mathrm{m}$ large water- or air-filled pores $)$ of cementitious materials by using ultrasonic waves generated by embedded Micromachined Ultrasonic Transducers (MUT) (figure 1a) [7]. Such approach fosters the use of MUT devices with an active surface in the $1 \mu \mathrm{m}^{2}$

\footnotetext{
${ }^{5}$ The first author performed the work while at CEA-LETI and IFSTTAR.

${ }^{6}$ The second author performed the work while at LIMOS UMR CNRS 6158, Clermont Université, France.
} 
range. As state-of-the-art MUT devices do not meet these surface requirements [8], we designed a new type of capacitive MUT (cMUT).

In a cMUT device, ultrasonic transduction is achieved by using the vibrations of a conducting membrane suspended above an actuation electrode. For our application, the span of the membrane had to be lowered by about one order of magnitude compared to existing devices, down to a micrometric size. To maintain significant amplitudes of vibration [9] and thus avoid sensitivity loss, the thickness of the membrane also had to be reduced to a nanometer size.

With conventional materials used for microelectronics, the fabrication of such a suspended membrane with micrometric size and nanometric thickness for ultrasonic transduction purposes presented a real challenge. We overcame it by using single-walled carbon nanotubes (SWNTs) instead as membrane material: in the new cMUT device discussed here, the ultra-thin membrane consists of a dense, fewlayered assembly of well-aligned SWNTs [10] (figure 1b). This paper presents some novel results we obtained while realizing such SWNT-based cMUT devices: after a brief description of the fabrication process, we present a quantitative analysis of the significant morphological features of the membranes as observed on SEM and AFM images. We also study the device vibrational behavior by laser vibrometry.
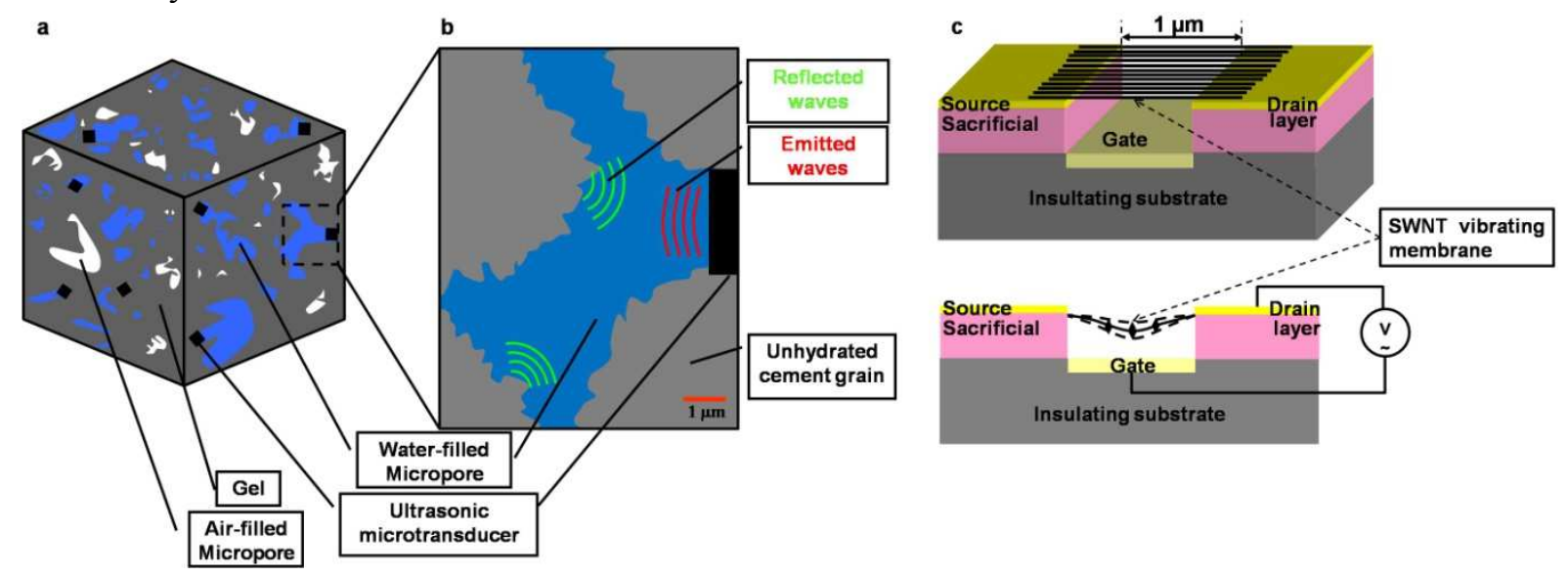

Figure 1. Instrumentation principle: (a) schematic representation of a cubic sample of cement gel (matrix in gray, air-filled pores in white, water-filled pores in blue) instrumented with a large number of randomly embedded ultrasonic microtransducers (black squares); (b) ultrasonic microtransducer (black rectangle) probing a water-filled pore in pulse-echo mode (emitted waves in red, reflected waves in green); c) Schematic representation the microtransducer: (top) single-walled carbon nanotubes are aligned to form the dense membrane of a capacitive ultrasonic microtransducer; (down) due to the electrostatic interaction between the gate electrode and the metallic membrane, the membrane vibrates upon application of a varying gate voltage.

\section{Device fabrication}

The devices are fabricated using SWNTs from Carbon Solution Inc synthesized by electric arc from $\mathrm{Ni} / \mathrm{Y}$ catalysts (the AP-SWNT product). SWNT are first purified by acidic treatment following the process described in [11] and then dispersed in N-methyl-2-pyrrolidone at low concentration using an ultrasonic bath (typically $70 \mathrm{~W}$ for $60 \mathrm{~min}$ ).

The still partially bundelized [12] nanotubes are deposited by dielectrophoresis [13]: an AC electric field (typically $5 \mathrm{~V} / \mu \mathrm{m}$ at $5 \mathrm{MHz}$ during $5 \mathrm{~min}$ ) is applied between two parallel, $1 \mathrm{~mm}$ long, metallic ( $\mathrm{Pt}$ or $\mathrm{Ti} / \mathrm{Au}$ ) electrodes deposited on a $\mathrm{SiO}_{2}$ layer and separated by $1 \mu \mathrm{m}$ or $2 \mu \mathrm{m}$; polarized by the electric field, the nanotubes are attracted to the electrodes and settle perpendicularly to them (figure 2a).

After deposition, the SWNT are anchored to the electrodes by $50 \mathrm{~nm}$ thin, $20 \mu \mathrm{m}$ large ribbons of Pt. These ribbons are patterned by e-beam lithography of PMMA 4\% resin, evaporation of $50 \mathrm{~nm}$ of Pt at $0.1 \mathrm{~nm} / \mathrm{s}$ and acetone lift-off of the resin.

Finally the membrane formed by the anchored SWNTs is released by removing the SiO2 layer either by dry etching (typically a focalized CHF3 plasma applied for $20 \mathrm{~s}$ at $40 \mathrm{~W}$ in a RIE reactor NEXTRAL NE 90A) or by wet etching (typically HF $10 \%$ during $5 \mathrm{~min}$ ) (figure $2 \mathrm{~b}$ ). We have no 
evidence of SWNT degradation after etching. However we observed that a longer exposure (more than a few minutes) of the SWNT to the CHF3 plasma will result in their complete etching.

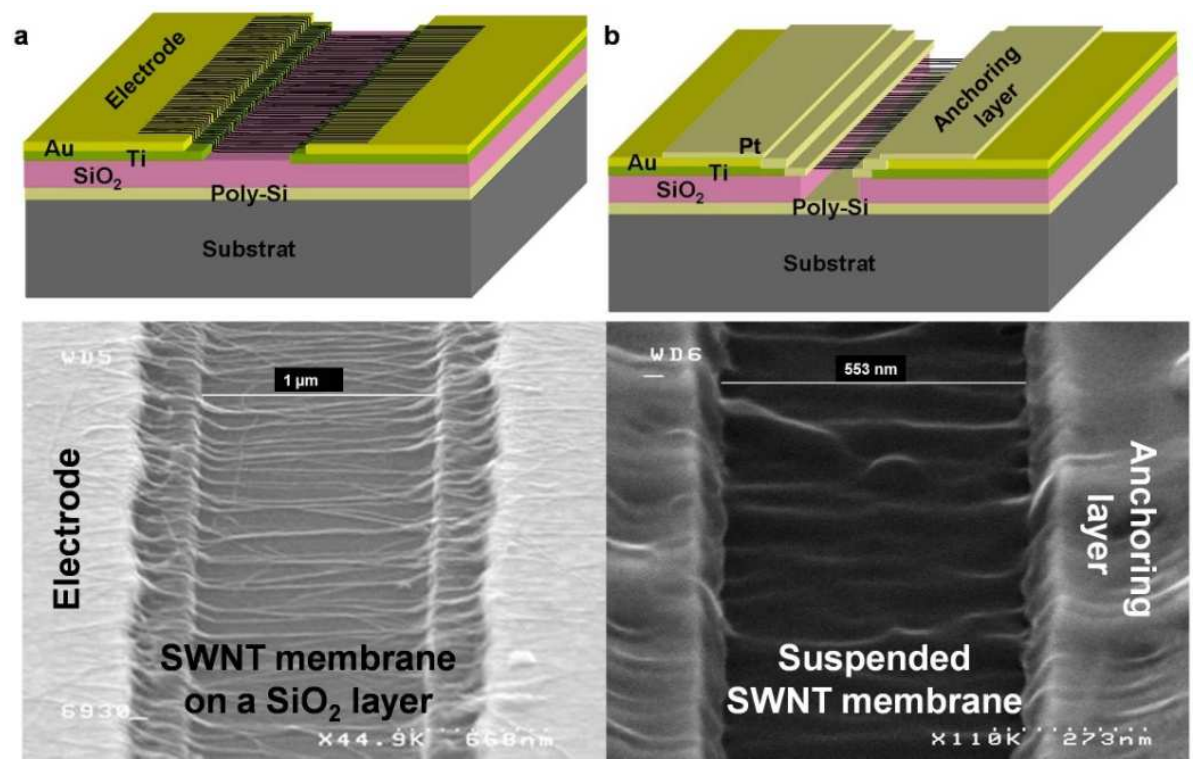

Figure 2. a) SWNT deposition: (top) schematic view of the substrate and of the deposited SWNTs; the electrode material can be either $\mathrm{Ti} / \mathrm{Au}$, as displayed here, or Pt. (bottom) SEM picture of a membrane of well-aligned, thin SWNT bundles deposited by dielectrophoresis between $\mathrm{Ti} / \mathrm{Au}$ electrodes on a $\mathrm{SiO}_{2}$ layer. b) Suspension of the SWNT membrane: (top) schematic view of the device featuring suspended SWNTs anchored on the electrodes by a thin metallic ribbon; (bottom) SEM picture of a membrane of SWNT bundles deposited between Ti/Au electrodes and suspended by RIE etching of the $\mathrm{SiO}_{2}$ layer. The material that glues the bundles together is interpreted as a thin PMMA layer remaining from the patterning process of the anchoring layer. Note that in both SEM pictures, the sample is tilted by $45^{\circ}$ to the electronic beam.

\section{Highly aligned and dense SWNT membranes}

\subsection{Optimization of the dielectrophoresis process}

Since the application is very demanding regarding to the membrane properties, the capabilities of the dielectrophoresis deposition process in terms of SNWT alignment and density have been extensively studied: over eighty depositions were realized and the resulting membranes were then imaged by SEM, until a proper control over the membrane features was achieved.

Several images ( 3 to 15 ) were needed for a proper characterization of each deposition, as the deposition area ranges from 1,000 to $2,000 \mu \mathrm{m}^{2}$, whereas each SEM image corresponds to a surface of only 1 to $2 \mu \mathrm{m}^{2}$. The whole set of SEM images (660 images) was taken in a SEM Hitachi S4000 or 4100 under $30 \mathrm{kV}$ acceleration voltage and $12 \mu \mathrm{A}$ emission current on samples tilted by $45^{\circ}$ to the electronic beam with a magnification chosen between 30,000 and 60,000.

Considering the large quantity and the complexity of the images, the often used "by hand" method [14] was not sufficient for quantitative analysis and objective comparisons. An automated image processing technique providing statistical quantities related to nanotubes orientation and density appeared highly desirable to validate the membrane fabrication process. It had to be able to process large sets of images with significant diversity.

\subsection{SEM images processing technique}

We implemented such a processing sequence (figure 3a-d). While requiring very little user supplied information, our procedure extracts quantitative characteristics of an assembly of filamentary objects. The initial images (figure 3a) are first denoised using the software GREYCStoration (based on an anisotropic diffusion equation) [15]. Resulting images are analyzed using the software MATLAB, and more specifically its IMAGE and DIFFC [16] toolboxes. Two main issues have to be solved, namely the segmentation of the filaments skeleton and the estimate of their local orientation. 
To begin with, the images are convoluted by short lines with every different possible orientation. Because nanotubes (or nanotubes bundles) are linear objects, this operation enhances the nanotubes, enabling the extraction of the pixels of the image that belong to nanotubes (figure $3 \mathrm{~b}$ ). The skeleton of the nanotubes is obtained by morphological thinning of each nanotube down to a line (figure $3 \mathrm{c}$ ).

The ratio of the skeleton total length to the gap width yields the number of nanotubes (or bundles) in the image, from which we derive the nanotubes linear density $d_{1}$ (number of nanotubes by unit length of deposition).

The orientation of each nanotube is derived at the position of each pixel of its skeleton by using local structure tensors (figure 3d). We thus obtain the skeleton angular distribution $\mathrm{p}(\alpha)$, defined by the percentage of the nanotubes total skeleton length whose orientation is comprised between $\alpha$ and $\alpha+180 / 256^{\circ}$, for $-90^{\circ}<\mathrm{a}<90^{\circ}-180 / 256^{\circ}$. From $\mathrm{p}(\alpha)$, we determine the order parameter of the deposition $S=<\cos ^{2}(\alpha)>=\int p(\alpha) \cos ^{2}(\alpha) d \alpha$, similar to the order parameters used in [17]. Note that the image tilt is taken into account in the analysis.

a

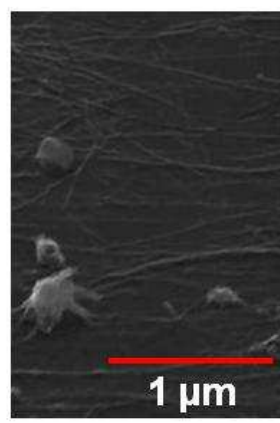

b

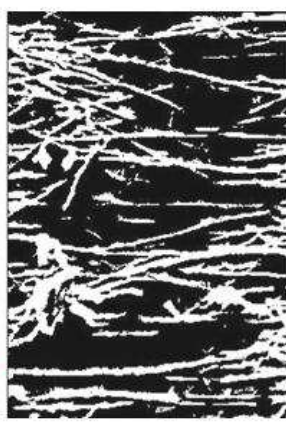

c

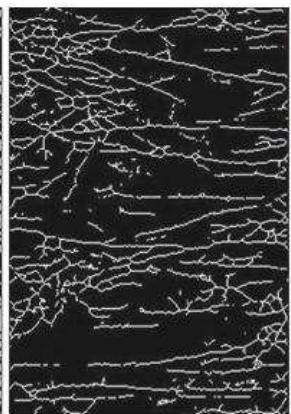

d

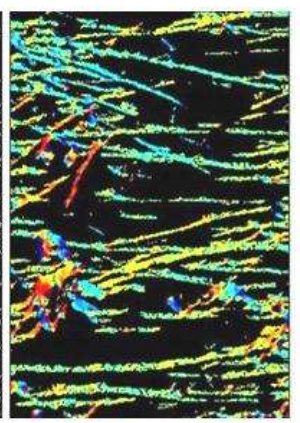

Figure 3: application of the image processing technique on a SWNT deposition of average quality (linear density $7 \mathrm{SWNT} / \mu \mathrm{m}$ and order parameter 0.74): a) SEM picture of the considered SWNT membrane (Magnification: 24,900; 45 $5^{\circ}$ tilt to the electronic beam). b) Extraction of the nanotubes pixels (in white) from the background (in black) by anisotropic contrast enhancement. c) Extraction of the skeleton by morphological thinning. d) Determination of the nanotubes orientation by gradient computation (colour code: from red $\left(-90^{\circ}\right)$ to light green $\left(0^{\circ}\right.$, i.e. alignment) to blue $\left(+90^{\circ}\right)$ ).

\subsection{Results of the SEM image analysis}

This image processing method enables the quantitative comparison of various depositions and thus the optimization of the deposition process. It makes the whole device fabrication process more efficient, as it enables the objective selection of only the samples with the best-aligned and densest nanotubes to be post-processed (anchoring and suspension steps).

The result of the image processing applied to the whole set of images is presented figure 4: the average order parameter ( 0.5 in absence of any preferential order, 1 in case of perfect ordering) is equal to 0.74 . Over single images, best alignment was found to be as high as 0.93 : more than $80 \%$ of the nanotubes are deposited with a tilt of less than $20^{\circ}$ to the horizontal axis. These values indicate the high quality of the SWNTs alignment [18].

In the literature, the linear density of an assembly of aligned nanotubes (bundles) is found to range from 2 bundles by micrometer (by in-place growth [19]) to 60 bundles (by Langmuir-Blodgett [20]) by micrometer. Here, the density of nanotubes reaches the intermediate value of 19 bundles by micrometer. Deposited layers appear to be made up of a single layer of SWNTs bundles (fig. 2a; fig. 3a-d), probably as a result from the screening effect commonly seen in SWNTs dielectrophoresis [21]. 


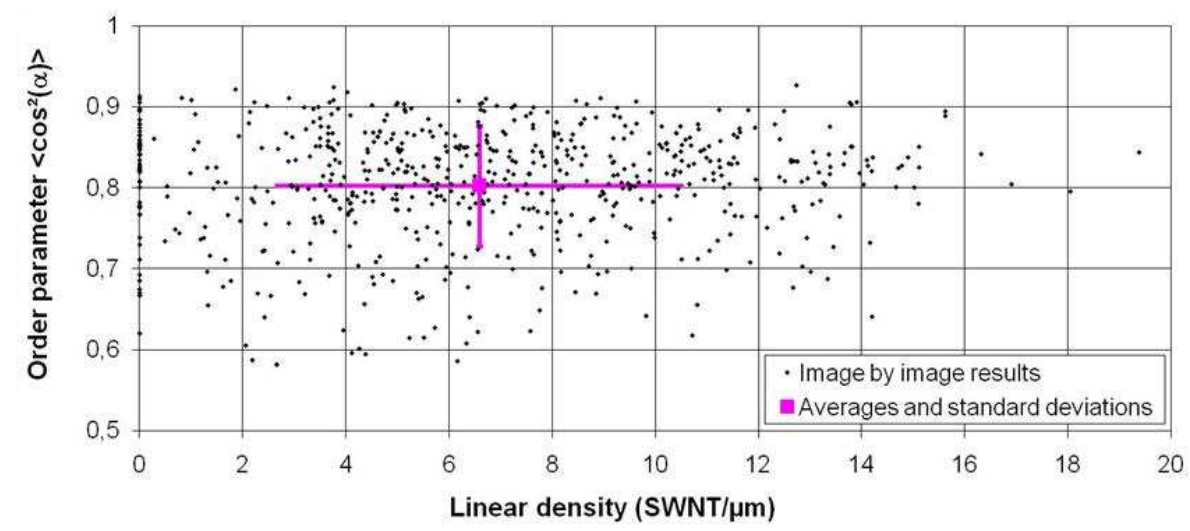

Figure 4: Result of the image processing applied on 660 SEM images taken on 87 different depositions: for each image, the graph presents the order parameter $\left\langle\cos ^{2}(\alpha)>\right.$ of the nanotubes angular distribution versus linear density (black dots); the pink square marks the position of the average of the order parameter and linear density distributions. The pink errors bars feature the standard deviation of these two distributions.

\section{Ultra-thin SWNT membranes}

As membrane thickness is critical to the application, we evaluated before suspension the thickness of three chosen samples by AFM profilometry in tapping mode [22].

We used a Multimode AFM equipped with a Nanoscope IIIa electronics from Bruker AXS with Aluminium-coated silicon tips (TAP300 Al-G, Budget Sensors). The typical tip radius is lower than $10 \mathrm{~nm} .512 \times 512$ pixels images of the sample height were acquired in tapping mode at the typical scan rate of $0.5 \mathrm{~Hz}$ ( 2 seconds by line). Pixel by pixel error on the height measurement is lower than 0.5 $\mathrm{nm}$.

We defined the sample thickness as the average of the height distribution, the substrate height being chosen as reference height. The convolution of the shape of the tip with small-size features (small compared to the tip radius) leads to an overestimation of the thickness (broadening effect). To correct this effect, images were first processed before the thickness is computed.

Among the three samples, two showed an average thickness of $10.7 \mathrm{~nm}$ (figure 5a). The third one showed an average thickness of $1.4 \pm 0.4 \mathrm{~nm}$ over a surface of about $0.06 \mu \mathrm{m}^{2}$ (figure $5 \mathrm{~b}$ ): hence this sample appears to be made of a monolayer of individual SWNTs. It is an exceptional feature among reported devices made of deposited SWNTs [20].
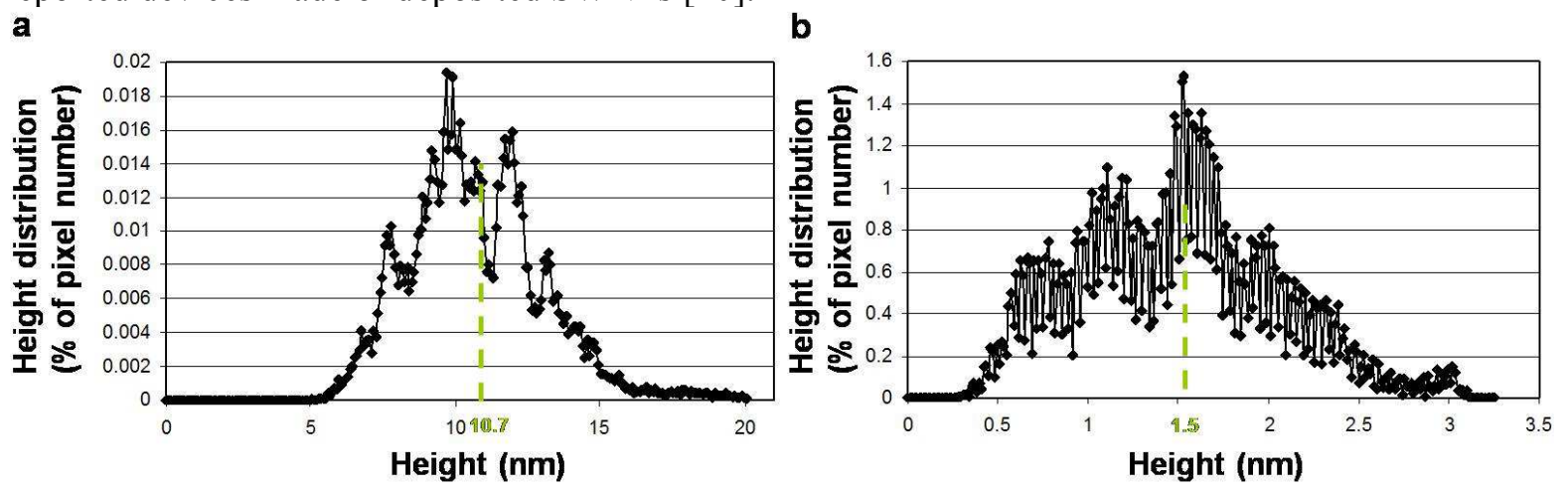

Figure 5: Height distribution of two SWNTs membranes obtained from AFM images: a) $10.7 \mathrm{~nm}$ and b) $1.4 \mathrm{~nm}$ thick membranes. The height of the $\mathrm{SiO} 2$ layer is the reference ("zero") height. The height distribution is expressed in percentage of the pixels number. The green line marks the average of the height distribution, which defines the sample thickness.

\section{Above-nanometer amplitudes of SWNT vibrations}

\subsection{Laser vibrometry}


To test the suitability of the fabricated devices for acoustic wave generation, we studied their vibratory behaviour. SWNT vibrations are often detected by electrical methods [23], where the amplitudes of vibration are determined indirectly by measuring some electrical parameters and feeding them to theoretical models. To measure directly the vibration amplitudes, an alternative method consists in using AFM vibration imaging [24].

Here, we chose to implement scanning laser Doppler vibrometry. The amplitudes of the membrane out-of-plane vibrations are measured by a scanning laser ( $\mathrm{He}-\mathrm{Ne})$ Doppler vibrometer Polytec MSA400. Points are typically acquired on a grid with controllable spacing (from $250 \mathrm{~nm}$ to $1 \mu \mathrm{m}$ in both directions). The instantaneous vertical speed of the membrane at each grid point is measured during 100 periods at a rate of 10 acquisitions by period. Then Polytec's dedicated PSV software derives the frequency spectrum of vibration and calculates the RMS amplitude of vibration (quadratic mean of the position over the measurement duration) at each grid point.

Until the present work, this technique had not been used with SWNT, as the laser beam is much larger than the SWNT diameter. Here, its use is enabled by the assembly of the SWNTs into a membrane with a density high enough to reflect the laser beam.

\subsection{Above nanometer amplitude of vibration}

For the measurements, we considered a membrane suspended over a $2 \mu \mathrm{m}$ wide trench and placed in air at ambient pressure and room temperature. The membrane was actuated electrostatically [23] by applying an AC voltage of typically $8 \mathrm{~V}$ peak-to-peak and an additional DC bias of typically $1 \mathrm{~V}$ to the actuating electrode underlying the $300 \mathrm{~nm}$ deep trench. The membrane itself was grounded via the top electrodes.

Under these conditions, we measured the vibrations of the membrane over a large range of frequencies spanning from $100 \mathrm{kHz}$ to $5 \mathrm{MHz}$. Figure 6 (left) shows an example of vibration profiles obtained at $100 \mathrm{kHz}$. The maximum peak-to-peak amplitude of vibration measured along the membrane was 5.6 $\mathrm{nm}$ at $3.7 \mathrm{MHz}$ (figure 6 right).

Such an amplitude of vibration, about as high as 4 times the diameter of the SWNTs composing the membrane $(1.4 \mathrm{~nm})$, makes the device compatible with low-frequency (below $20 \mathrm{MHz}$ ) [25] vibrations detection system.

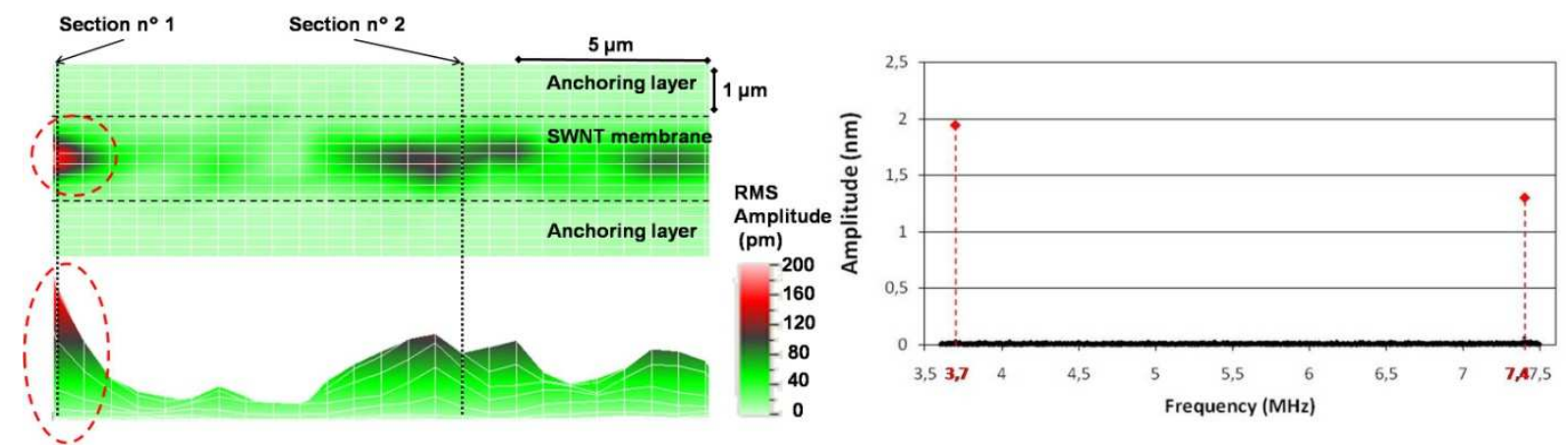

Figure 6: Demonstration of membrane vibrations using scanning laser vibrometry. (Left top) top view and (left bottom) side view of the RMS amplitude of vibration of a $2 \mu \mathrm{m}$ wide membrane at $100 \mathrm{kHz}$ under a bias voltage $\mathrm{V}_{\mathrm{DC}}=1 \mathrm{~V}$ and an alternating voltage of $\mathrm{V}_{\mathrm{AC}}=8 \mathrm{Vpp}$. The membrane, delimited by the two horizontal dashed lines, vibrates with different amplitudes along its length, depending on its local properties such as thickness, bundles crossing and trapped impurities. The superimposed white grid shows the effective points of measurement by the scanning vibrometer. The RMS amplitude of noise is $30 \mathrm{pm}$ (RMS amplitude of vibration measured on the motionless anchoring layer). The maximal RMS amplitude of vibration (measured approximately at the center of the dashed circle) is $200 \mathrm{pm}$. (Right) Focus on the membrane location with largest amplitude of vibrations (located within the red circle): Frequency spectrum of vibration measured under a bias voltage $V_{D C}=1 \mathrm{~V}$ and an $A C$ voltage $\mathrm{V}_{\mathrm{AC}}=8 \mathrm{Vpp}$ applied at $3.7 \mathrm{MHz}$. As a bias voltage is applied, the vibration spectrum is made of two Dirac peaks signaled by the red lozenges, one at $3.7 \mathrm{MHz}$, the second at twice this frequency, 7.4 MHz. RMS and peak-to-peak amplitudes of vibration are respectively $1.7 \mathrm{~nm}$ and $5.6 \mathrm{~nm}$. Noise level is below $65 \mathrm{pm}$. 


\section{SWNT-based cMUT devices for durability monitoring in multiphasic porous materials} According to an advanced numerical microfluidic model of the proposed cMUT devices [26], their low-frequency amplitudes of vibration are expected to be four orders of magnitude higher in air than in a liquid environment. Their first resonance frequency in water should be in inverse proportion to the pore size.

Hence, if the proposed sensors were to be embedded in large number in a multiphasic porous material (concrete, bones or oil reservoirs), they could differentiate air-filled micropores from other liquidfilled pores and determine the size of water-filled pores. Such in-situ data could then be effectively exploited to monitor hydration, water-related degradations and durability [27] with an unprecedented spatial resolution.

\section{Conclusion}

As a summary, we fabricated particularly well-aligned, ultra-thin, dense suspended membranes of SWNT. To our knowledge, some of our membranes feature the highest order parameter and lowest thickness ever reported for dielectrophoresis deposition of SWNT. By using scanning laser Doppler vibrometry, we showed that these membranes can feature above-nanometer amplitude of vibrations. It appears to be the first report on laser vibrometry being applied to measure the amplitude of vibrations of SWNTs. The large amplitudes of vibrations we measured indicate the feasibility of SWNT-based cMUT devices. They are the first type of nanodevices whose use is realistically envisioned for in-situ durability monitoring of porous materials at the micro-scale.

\section{Acknowledgments}

The authors thank J. C. Gabriel for helpful discussion. This work was in part achieved at the PTA (Up-line Technological Platform) facility in Grenoble (http://www.pta-grenoble.com/).

\section{References}

[1] Galiana I and Green C 2009 Nature 462 570-1

Fernández J E 2007 Science 315 1807-10

[2] van Broekhuizen F and van Broekhuizen P Nano-products in the European Construction Industry - State of the Art 2009 Report commissioned by EFBWW and FIEC

[3] Wagner H D 2007 Nat. Nanotechnol. 2 742-4

[4] Konsta-Gdoutos M S, Metaxa Z S and Shah S P 2010 Cement Concrete Res. 40 1052-59

[5] Saafi M 2009 Nanotechnology 30395502

Li X, Levy C and Elaadil L 2008 Nanotechnology 19045501

[6] Sorelli L, ConstantinidesG, Ulm F-J and Toutlemonde F 2008 Cement Concrete Res. 38 1447-56

Baroghel-Bouny V, Nguyen T Q and Dangla P 2009 Cement Concrete Comp. $200931522-34$

[7] Lebental B, Ghis A and Delevoye E 2010 WO Patent WO/2010/057,990

[8] Ndieguene A et al. 2009 J. Phys. Conf. Ser. 195 012005-14

Logan A and Yeow J T 2009 IEEE T. Ultrason. Ferr. 56 1074-84

[9] Timoshenko S and Goodier J N 1951 Theory of elasticity ed.McGraw-Hill Book Compagny 195 pages

[10] Lebental B and Ghis A 2010 WO Patent WO/2010/057,992

[11] Schmidt G, Gallon S, Esnouf S, Bourguoin J P and Chenevier P 2009 Chemistry- A European Journal 15 2101-10

[12] Furtado C A et al. 2004 J. Am. Chem. Soc.126 6095-105

[13] Dimaki M and Boggild P 2004 Nanotechnology 15 1095-102

[14] Russel J M, Oh S, La Rue I, Zhou O. and Samulski E T 2006 Thin solid films 509 53-7

[15] Tschumperlé D 2006 Int. J. Comput. Vision 68 65-82 http://gmic.sourceforge.net/index.shtml

[16] Peyré G 2004 Toolbox DIFFC http://www.mathworks.com/matlabcentral/fileexchange/5103

[17] Lynch M D and Patrick D L 2002 Nano Lett. 2 1197-201

Lagerwall J et al. 2007 Adv. Mater. 19 359-64

[18] Krupke R, Hennrich F, van Löhneysen H. and Kappes M M 2003 Science 301 344-7 
Lu M, Jang M-W, Haugstad G, Campbell S A and Cui T 2009 App. Phys. Lett. 94261903

[19] Kocabas C, Shim M and Rogers J A 2006 J. Am. Chem. Soc. 126 4540-1

Ren L et al. 2009 Nano Lett. 9 2610-3

[20] Li X et al. 2007 J. Am. Chem. Soc. 129 4890-1

[21] Vijayaraghavan A et al. 2007 Nano Lett. 7 1556-60

[22] Avlyanov J K, Josefowicz J Y and Mac Diarmid A G1995 Synthetic Met. 73 205-8

[23] Sazonova V et al. 2004 Nature 431 284-7

van der Zande A M et al. 2010 Nano Lett. 10 4869-73

Arun Aet al. 2011 Nanotechnology 22055204

[24] San Paulo A et al. 2008 J. Phys. Conf. Ser. 100052009

Kwon O-H, Park H S, Baskin J S and Zewail A H 2010 Nano Letters 10 3190-8

[25] Arcamone J et al. 2008 Nanotechnology 19305302

Colinet E et al. 2008 IEEE International Solid-State Circuits Conference 18332

[26] Lebental B, Ghis A, Delevoye E, Caussignac J-M and Bourquin F 2011 Eur. J. Env. Civ. Eng. 15 649-62

[27] Boumiz A, Vernet C and F. Cohen Tanoudji 1996 Adv. Cem. Based Mater 3 94-106

Kumar R and Bhattacharjee B 2004 Cement Concrete Res. 34 321-8 